\title{
ANALYSIS OF INSULATING PARAMETERS OF OIL TRANSFORMER BY TIME AND FREQUENCY METHODS
}

\section{Miroslav GUTTEN, Matej KUCERA, Peter BRNCAL, Milan SEBOK, Daniel KORENCIAK}

Department of Measurement and Application Electrical Engineering, Faculty of Electrical Engineering and Information Technology, University of Žilina, Univerzitna 1, 01026 Zilina, Slovakia, Email: miroslav.gutten@fel.uniza.sk, matej.kucera@ fel.uniza.sk, peter.brncal@ fel.uniza.sk, milan.sebok@fel.uniza.sk, daniel.korenciak@fel.uniza.sk

Abstract

In the paper is presented experimental analysis and diagnostics of insulating system oil-paper for power transformers. In the first part of the paper is described base theory about measurement and diagnostics insulating part (oil and paper) of transformers. In the other two parts of the paper is presented experimental results of the diagnostic measurement for the transformer $22 / 0.4 \mathrm{kV}$ at constant temperature. Specifically, in the second part is described measuring time method of insulating diagnostics - return voltage measurement (RVM). This method is used for analysis of condition of paper moisture of high-voltage equipment. In the third part is described measuring method of insulating frequency diagnostics - frequency domain spectroscopy (FDS). This method is used for analysis insulating condition of high-voltage equipment with insulating oil-paper. The both measuring methods are unique in terms of analysis of insulating system of oil power transformers. In comparison with other methods, the RVM and FDS methods it is possible comparison and evaluate the moisture state of the dielectric paper of the power transformer with high reliability and accurate. Their reliability in determining moisture in paper was shown by determining the same result (3.5\%) on the same measured transformer.

Keywords: insulating system, transformer, return voltage measurement, frequency dielectric spectroscopy

\section{INTRODUCTION}

Influence of operating conditions leads to aging of individual parts of transformer, and also to changes of the major electrical and mechanical properties. To the check of the condition greatly contributes electro-technical diagnosis, whose main task is to find a clear relation between the change in functional characteristics of the machine and some measurable values. The assessment of these measured values must be visible not only the rate of change, but also whether it is a permanent or reversible state. The aim of diagnostics of transformers is to verify that the machine complies with the determined conditions in accordance with standards [1].

Insulation diagnostics is one of the requirements for safe operation of transformers. Conventional methods to assessment of insulation condition are its loss factor, insulation resistance and partial discharge measurement, etc. These methods, however, provide only partial picture about the polarization processes in insulating material.

Deregulation of power market has increased the competition and also emphasized on the search for the new, efficient and effective methods for diagnosing the insulating system. The use of the return voltage method is significant way to detect ageing of the insulation of operating power transformer in a non-destructive manner [2].
To prevent a damage state of transformers, we perform different types of the measurements that should illustrate an actual condition of the measured equipment. It is therefore important to choose a suitable diagnostics for the right prediction of such conditions [3], [4].

In Fig. 1 are showed basic diagram of costs for operation and maintenance of power transformers from $110 \mathrm{kV}$ (transfer and distribution system).

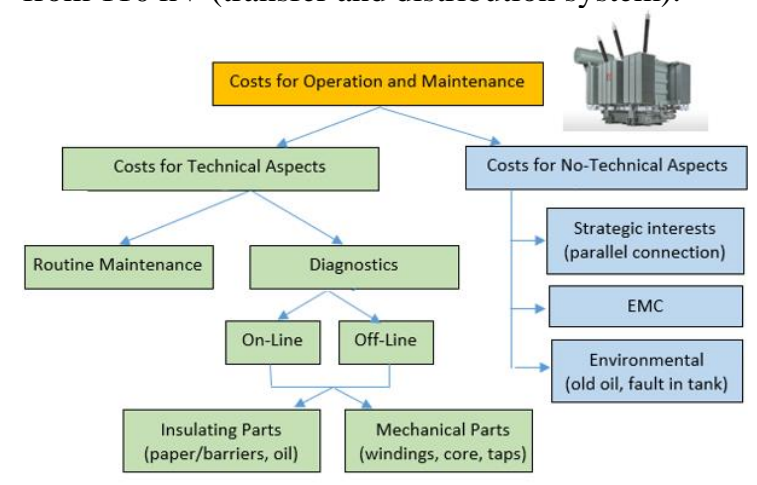

Fig. 1. Basic diagram of costs for operation a nad maintance of power transformer.

\section{DIAGNOSTICS OF THE TRANSFORMER INSULATION BY TIME METHODS}

In nowadays is possible to capture very low current involved in dielectric relaxation process. This is door open to technique like RVM (Return 
Voltage Measurement) or PDC (Polarization Depolarization Current). Those techniques have been introduced in 90's. This measurements technique has gained popularity for its ability to assess the condition of oil and paper separately without opening the transformer tank [5].

For PDC analysis is DC voltage step of some $100 \mathrm{~V}$ is applied between HW (high voltage) and LV (low voltage) windings during a certain time, the so-called polarization duration. Thus a charging current of the transformer capacitance, i.e. insulation system, the so-called polarization current, flows. It is a pulse-like current during the instant of voltage application which decreases during the polarization duration to a certain value given by the conductivity of the insulation system.

The RVM method (Fig. 2) consists of plotting the measured maximum response times with respect to the charging time, from which it is possible to determine the moisture content of the insulation in high-voltage oil equipment. In general, this method is intended for non-destructive, off-line determination of the state of the isolation system of transformers, cables or other devices that are comprised of the conductor and the insulator [6-7].

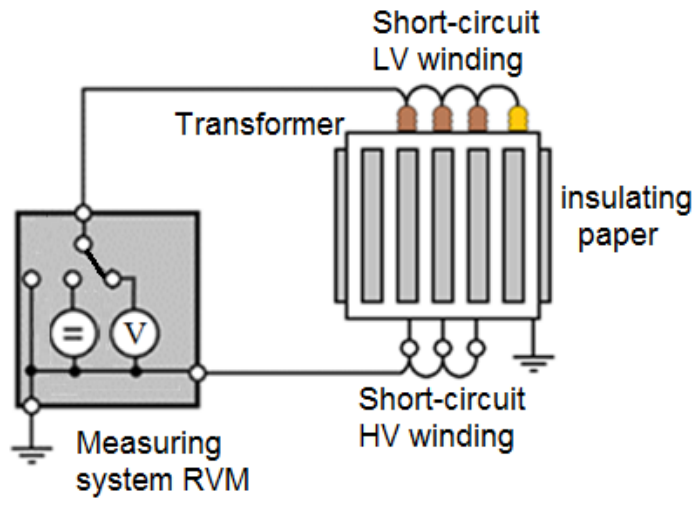

Fig. 2. Principal scheme of RVM measuring system.

If the method is applied to an oil transformer, it determines the moisture content at the oil-paper dividing line. Measured values determine the time constant and the slope of the voltage response rise.

Based on the relationships listed in [8], paper moisture and conductivity in oil can be calculated with sufficient precision.

\section{DIAGNOSTICS OF THE TRANSFORMER INSULATION BY FREQUENCY METHOD FDS}

Previous research works in condition monitoring of electrical insulation have indicated that the frequency domain spectroscopy can the most effectively estimate deterioration in Oil-Paper Insulation in power transformer. Since especially the low frequencies (to $0.1 \mathrm{~Hz}$ ) reflect moisture concentration, their measurement is of outmost importance for reliable data analysis. Beside a frequency sweep, the response of a dielectric to a voltage sweep is experimentally investigated and discussed [9], [10].

Special focus is given on a comparison of the currently available dielectric spectroscopy methods to traditional measurement techniques like dielectric dissipation factor $(\operatorname{tg} \delta)$ tests at power frequency and $0.1 \mathrm{~Hz}$, dielectric adsorption ratio and the polarization index. The traditional methods suffer from a limited time or frequency range which impedes the discrimination of specific dielectric properties [11], [12].

If for example increased losses appear, it is impossible to discriminate whether they are caused by the insulating oil or the cellulose paper insulation. In the Fig. 3 is showed insulating system of distribution transformer for its one phase column.

Applying a sinus frequency sweep in wide range means to measurement the dielectric response in depending on quality transformer insulate [13], [14].

Dielectric response of the whole insulation system in transformer depends on different factors i.e. on the properties of impregnated paper and pressboard, on the properties of oil, and on the geometrical arrangement of the system components and a correct evaluation of the measured data involves mathematical modelling, which requires knowledge on variation of the oil and paper/pressboard properties with temperature and moisture [15].

For power transformers insulated oil-paper, the dielectric response consists of three components. They are the response of the cellulose insulation (paper, pressboard), the response of the oil and the interfacial polarization effect. Moisture, temperature, insulation geometry, oil conductivity and conductive aging by-products influence the dielectric response [16].

\section{Phase column of transformer}

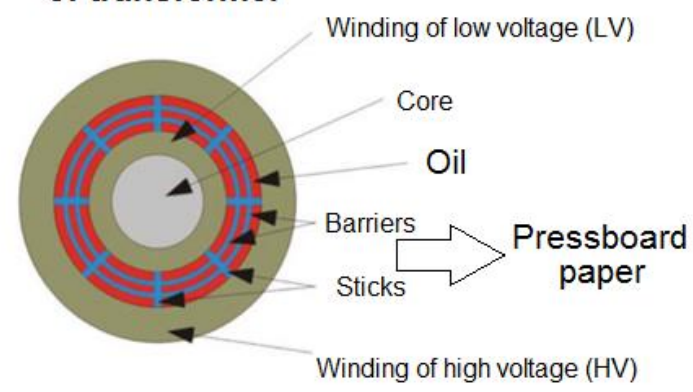

Fig. 3. Top view of the phase column of distribution transformer with insulating system

In the Fig. 4 is showed frequency dependence of dissipation factor for pressboard paper having moisture of $1 \%$ content and oil together with the effect of interfacial polarization (insulation geometry). The range of frequency from 1000 to 10 $\mathrm{Hz}$ is dominated by the insulation of cellulose. 
Dissolved conductive aging of elements of transformer its soot and high molecular weight acids increase the conductivity of oil and thus influence this area. The interfacial polarization (ratio of oil to pressboard, insulation geometry) determines the local maximum or "hump" at 0.003 $\mathrm{Hz}$ [9], [10].

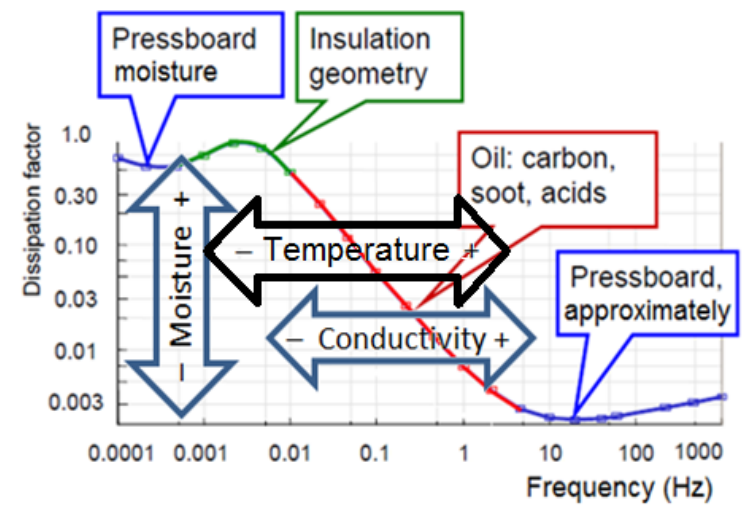

Fig. 4. Analysis of insulating transformer properties by curve of FDS method

The frequency limits correspond according to Fig. 4, but will vary in a wide range with moisture, conductivity of oil, insulation temperature, geometry and amount of conductive aging byproducts. Moisture particularly increases the losses in the low frequency range of the dielectric response of pressboard. For the point of inflexion on the left hand side of the area dominated by insulation geometry is required for a reliable moisture determination [9].

\section{EXPERIMENTAL MEASUREMENT AT DISTRIBUTION TRANSFORMER}

On the basis of theoretical analysis realized in the first phase of solution in the paper, there were determined the latest diagnostic insulating methods - time and frequency measuring techniques. As measured equipment was used distribution transformer $22 \mathrm{kV} / 0.4 \mathrm{kV}$ with power $30 \mathrm{kVA}$.

Our task was to compare the sensitivity of the two methods - time RVM method and FDS method by frequency response.

The RVM and FDS methods enable to determine the time response or frequency response of insulating parameters of transformers. Measurement of a response in the time domain means finding out of time course to a certain voltage proceedings in insulating paper system.

Measurement of a response in the frequency domain consist finding out of current of a response to the harmonic voltage with a variable frequency in whole and particular part of insulating transformer system.

\subsection{DIAGNOSTICS OF THE TRANSFORMER BY RVM METHOD}

The evaluation of the measurement and therefore the determination of the moisture content in the paper part of the isolation system of the oil transformer $22 / 0.4 \mathrm{kV}$ can be determined from the analysis of the charging time and the maximum $U_{\max }$ voltage response according to Fig. 5 till Fig. 7. Principal scheme of RVM measuring system is in Fig. 2.

For this evaluation, it is sufficient to write real time and measured voltage to the SD card. From this stored text document, time and voltage values are evaluated on a separate $\mathrm{PC}$ in one of the available computational programs. For better orientation, the creation time is also indicated.

Measurement of the voltage response depends largely on the temperature difference between the object and the surroundings. Since the measured transformer is unconnected to the grid and is located in the laboratory, the temperature difference is zero [9]. This is confirmed by measuring the winding temperature on the transformer by incorporating the Neoptix temperature probes and measuring the outside temperature with a $22^{\circ} \mathrm{C}$ by measuring thermometer.

The advance of RVM method is shown in the Fig. 5 and the graphic advance with the peak value of the measured voltage, depending in the measured time is in the Fig. 6.

Measurement of return voltage by RVM method consists of the four steps of Fig. 5 [10]. In the first step, the transformer terminals of $\mathrm{LV}$ and $\mathrm{HV}$ are connected to the test voltage for the charging time $t_{\mathrm{N}}$. This first step is called as charging. In the second step, there is a discharge for $t_{\mathrm{V}}=t_{\mathrm{N}} / 2$, where the LV and HV terminals are short-circuited. This second step is called as discharging. In the third step, the measurement of the voltage response and the time itself is carried out until the maximum voltage is reached. The last fourth step of measuring the voltage response consists of a recovery before another cycle for a time at least equal to $t_{\mathrm{N}}$.

The time behaviour and the individual measurement steps are shown in the Fig. 5 and the graphical representation with the maximum value of the measured voltage response values, depending on the charging time, is shown in the Fig. 6a.

The measurement of the voltage response of the insulation system consists of determining the moisture content of the paper part. This determination is derived from the characteristics of Fig. 6b, which are obtained by actual measurements on samples of different moisture at different temperatures. These evaluation curves in another version are also reported in the literature [8]. 


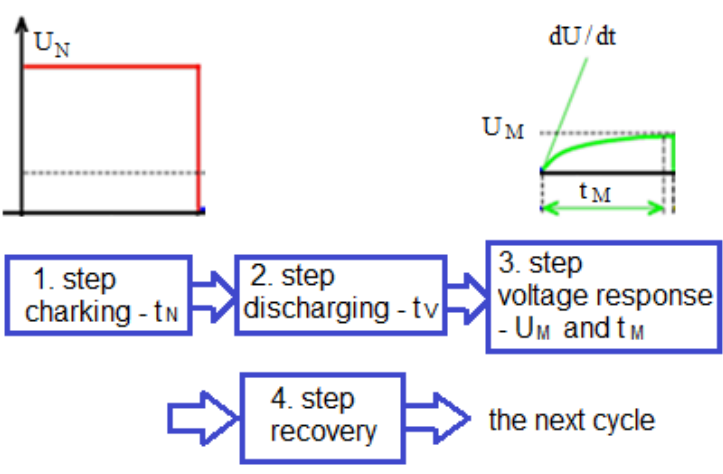

Fig. 5. The shape of the test voltage by RVM method

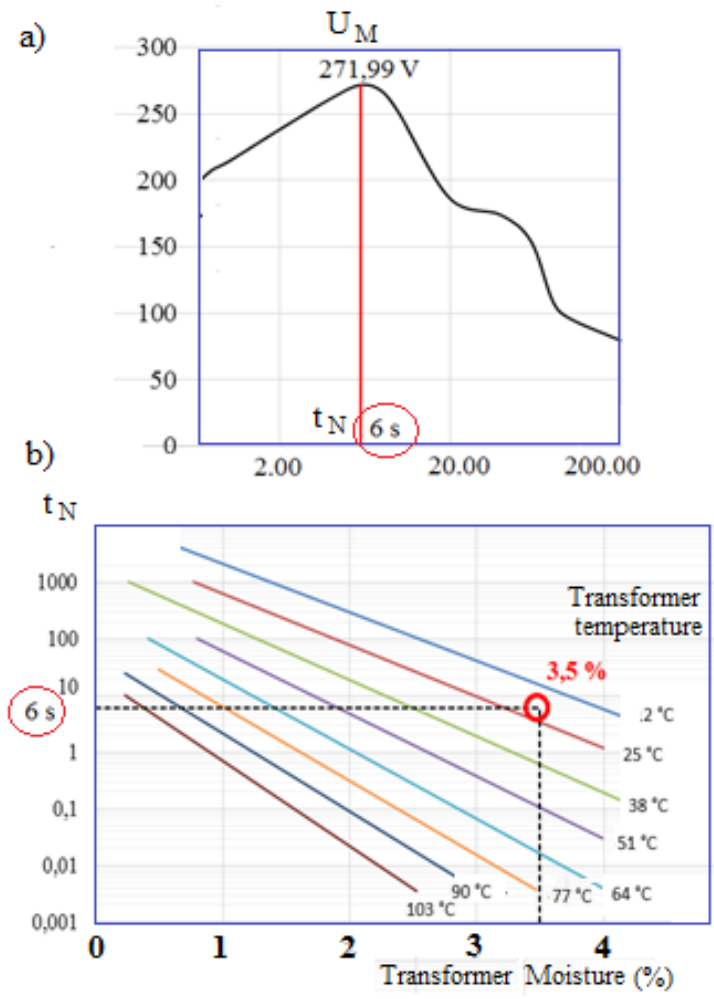

Fig. 6. Moisture analysis of insulating system the measured transformer by method RVM: a) the time behaviour of voltage response, b) evaluation curves for the voltage response

In Fig. $6 b$ is shown the intercept point for moisture content of $3.5 \%$ corresponding to the highest possible moisture value in the paper section of the transformer insulation. Since the moisture content was also controlled by the dielectric spectroscopy with method of frequency response and the result of the evaluation was the same, it is obvious that no significant amount of sludge is deposited on the paper. The suspension itself in the transformer oil does not have a more serious effect on the result of this measurement.

\subsection{DIAGNOSTICS OF THE TRANSFORMER BY FDS METHOD}

Measurement of the frequency response of the isolation system or measurement by the frequency domain spectroscopy (FDS) method is performed by the MEGGER IDAX 350 instrument. In this method it was measured parameters - the percentage loss factor, capacities and permittivity depending on the frequency of $10 \mathrm{kHz}$ up to $1 \mathrm{mHz}$ in the sinusoidal power supply $140 \mathrm{~V}_{\mathrm{ef}}$.

In Fig. 7 is showed the connection diagram for measuring the frequency response of the insulation on distribution transformer $22 / 0.4 \mathrm{kV}$.

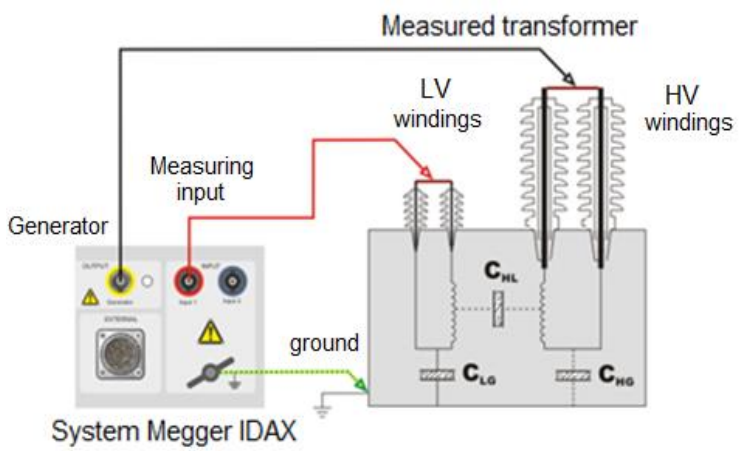

Fig. 7. Connection of the system MEGGER IDAX-350 to the measured distribution transformer $22 / 0.4 \mathrm{kV}$

Because measurement is performed at very low currents, it is necessary consistently linking all connections according to Fig. 7. Since the device separately distinguishes measurement of individual capacities, it is necessary to thoroughly clean the location for connection of the ground conductor of the device [17].

The processes in Fig. 8 show the measured characteristics of the loss factor $(\operatorname{tg} \delta)$ and the power factor $(\cos \varphi)$ between the windings, depending on the frequency of the harmonic supply.

In Fig. 9 is shown frequency depending of the whole and imaginary capacities ( $\mathrm{C}$ and $\mathrm{C}$ ').

From the entered values of temperature, moisture and transformer parameters, the modelling curves are calculated by the IDAX 350 program. Depending on the deviation of the measured waveforms from the model, the parameters of the transformer isolating system are subsequently determined.

Calculated values of paper moisture, oil conductivity and resulting of measured transformer are showed in Table 1. Since the temperature of the object being measured and the surrounding area is equal, no further conversion error is taken into account.

As it is shown in the evaluation Table 1, the isolation system of the tested transformer is considerably impaired. The values of the loss factor, moisture in paper and conductivity in oil show complexly to the poor state of the insulation system of measured transformer. 


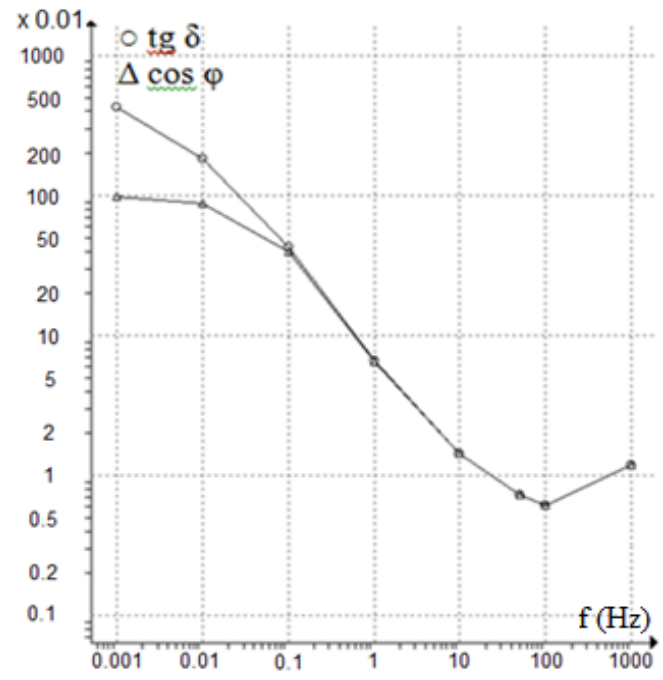

Fig. 8. Frequency depending of the loss factor $(\operatorname{tg} \delta)$ and the power factor $(\cos \varphi)$

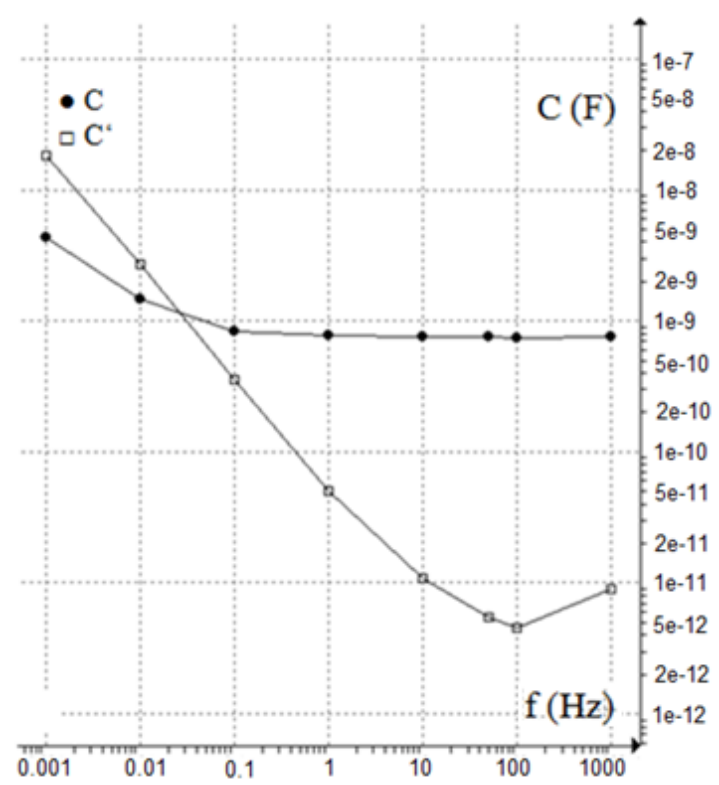

Fig. 9. Frequency depending of the whole and imaginary capacities ( $\mathrm{C}$ and $\mathrm{C}^{\prime}$ )

Tab. 1. Measured parameters of transformer insulating system $22 / 0.4 \mathrm{kV}$

\begin{tabular}{|c|c|c|c|c|}
\hline $\begin{array}{c}\text { Transfor- } \\
\text { mer } \\
\text { tempera- } \\
\text { ture } \\
{ }^{\circ} \mathrm{C}\end{array}$ & $\begin{array}{c}\text { Loss } \\
\text { factor } \\
\operatorname{tg} \delta \text { at } \\
20{ }^{\circ} \mathrm{C}\end{array}$ & $\begin{array}{c}\text { Moistu- } \\
\text { re in } \\
\text { paper } \\
\%\end{array}$ & $\begin{array}{c}\text { Condu- } \\
\text { ctivity } \\
\text { in oil } \\
\mathrm{pS} / \mathrm{m}\end{array}$ & $\begin{array}{c}\text { Evalu- } \\
\text { ation } \\
\text { paper/ } \\
\text { oil }\end{array}$ \\
\hline 21.2 & 0.75 & $\mathbf{3 . 5}$ & 5.514 & $4 / 4.5$ \\
\hline \multicolumn{5}{|c|}{$1-2:$ new/new, 2-3: dry/good, } \\
\hline \multicolumn{3}{|c|}{ 3-4: slightly wet/service old, 4-5: wet/worse } \\
\hline
\end{tabular}

\section{CONCLUSION}

In this paper we present an experiment for diagnostics and measurement of insulating parameters of high-voltage traction transformer by using frequency dielectric spectroscopy and return voltage method.

The both measuring methods are unique in terms of analysis of insulating system of oil power transformers. In comparison with other methods, the RVM and FDS methods can evaluate the moisture condition of the insulation paper of the power transformer with high accurate. Their reliability in determining moisture in paper was shown by determining the same result $(3.5 \%)$ on the same measured distribution transformer.

The advantage of the RVM method compared to the FDS method is in determining of transformer moisture for shorter time than at method FDS. At accuracy identification of transformer moisture at the frequency method it is possible time from one and half hour.

For method RVM, in which the maximum voltage response is reached at shorter charging times, the moisture content of the insulation is greater, what is the problem. The maximum voltage response of the new transformers is achieved with longer charging times. From high accurate measurement it has been found a necessary to attach a sufficiently large high voltage (from $2 \mathrm{kV}$ ).

The advantage of the FDS method compared to the RVM method is in determining the conductivity value of the oil and the loss factor (including the total transformer insulation system). The disadvantage of the FDS method is the need to measure very small currents. It is necessary to use shaded measuring cables.

From the point of view of protection from interference of stray currents for both methods it is precise determination of the moisture content in the transformer paper is very complicated, but in general, the appropriate cable shielding of measuring system and good grounding of measured equipment helps for better accuracy of evaluation of transformer insulating state.

\section{ACKNOWLEDGMENTS}

This work was supported by the Grant Agency VEGA from the Ministry of Education of Slovak Republic under contract 1/0471/20.

\section{REFERENCES}

1. Brandt, M. Identification failure of 3 MVA furnace transformer. IDEMISEE 2016, Papradno, SR, 2016: 6-10.

2. Monatanari GC. Polarization and space charge behavior of unaged and electrically aged crosslinked polyethylene. IEEE Trans. Dielectr. Electr. Insul. 2000: 474-479. https://doi.org/10.1109/94.868064.

3. Heatcote MJ. The J \& P Transformer Book 13th edition. Chennai: ELSEVIER. 2007.

4. Petras J, Kurimsky J, Balogh J, Cimbala R, Dzmura, J, Dolnik B, Kolcunova I. Thermally stimulated acoustic energy shift in transformer oil. Acta Acustica United with Acustica. 2016;102(1):16-22. https://doi.org/10.3813/AAA.918920. 
5. Glowacz A. Acoustic-Based Fault Diagnosis of Commutator Motor. Journal of Magnetism and Magnetic Materials. Electronics. 2018;7(11):299. https://doi.org/10.3390/electronics7110299

6. Glowacz, A. Acoustic fault analysis of three commutator motors. Mechanical Systems And Signal Processing. 2019;133: 106226. https://doi.org/10.1016/j.ymssp.2019.07.007

7. Shayegani AA, Hassan O, Borsi H, Gockenbach E, Mosheni H. PDC measurement evaluation on oilpressboard samples. International Conference on Solid Dielectrics. 2004; 4: 50-62.

8. Leibfried T, Kachler AJ. insulation diagnostics on power transformers using the polarisation and depolarisation current (PDC) analysis. International Symposium on Electrical Insulation. 2002;10:170173.

9. Koch M, Krueger M, Puetter M. Advanced insulation diagnostic by dielectric spectroscopy. Omicron Electronics Austria, 2011.

10. Koch M, Tenbohlen S, Krüger M, Kraetge A. A Comparative Test and Consequent Improvements on Dielectric Response Methods. Proceedings of the XVth International Symposium on High Voltage Engineering, ISH, Ljubljana, Slovenia, 2007.

11. Koch M. Reliable moisture determination in power transformers. $\mathrm{PhD}$ thesis, Institute of Energy Transmission and High Voltage Engineering, University of Stuttgart, Sierke Verlag Göttingen, Germany, 2008.

12. Koch M, Kruger M. Moisture determination by improved on-site diagnostics. TechCon Asia Pacific, Sydney 2008.

13. Glowacz A, Glowacz W. Vibration based fault diagnosis of commutator motor. Shock and Vibration. 2018:7460419 https://doi.org/10.1155/2018/7460419

14. Šulka P, Sapietová A, Bárnik F. Vibrodiagnostics of rolling ball bearings connected with processing, result's comparison and prediction of service life. Scientific Journal of Silesian University of Technology. Series Transport. 2020; 106: 183-196. https://doi.org/10.20858/sjsutst.2020.106.16

15. Neimanis R. On estimation of moisture content in mass impregnated distribution cables. Stockholm: Royal Institute of Technology Stockholm, 2001.

16. Andrearczyk A, Bagiński P. Vibration analysis of a turbocharger with an additively manufactured compressor wheel. Scientific Journal of Silesian University of Technology. Series Transport. 2020; 107:05-17. https://doi.org/10.20858/sjsutst.2020.107.1

17. Manual Megger IDAX 350

Received 2020-06-17

Accepted 2020-10-19

Available online 2020-11-10

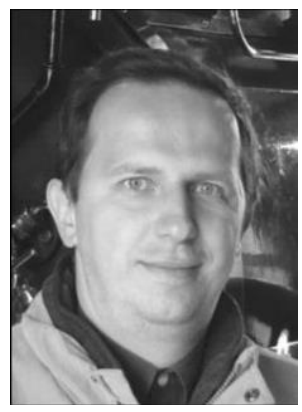

Prof. Miroslav GUTTEN (in the photo), PhD.; Ing. Matej KUCERA, PhD.; Ing. Peter BRNCAL; Doc. Ing. Milan SEBOK, $\mathrm{PhD}$; Doc. Ing. Daniel KORENCIAK, PhD.: University of Zilina participating organization in its scientific and research activities is dealing for several years with the solution of the project and grant tasks in area of diagnostics of electrical equipment (electrical machines, automotive systems, electrical transfer devices). Head of research team and Department of Measurement and Application Electrical Engineering is Prof. Miroslav Gutten, PhD. 